\title{
Molecular Cloning, Expression, and Chromosomal Localization of the Gene Encoding a Human Myeloid Membrane Antigen (gp150)
}

\author{
A. Thomas Look, $¥$ Stephen C. Peiper, $¥ \$$ Matthew B. Rebentisch," Richard A. Ashmun, ${ }^{\star}$ Martine F. Roussel, $\neq$ \\ Richard S. Lemons,‡ Michelle M. Le Beau," Charles M. Rubin," and Charles J. Sherr; \\ Departments of *Hematology-Oncology, $\ddagger$ Tumor Cell Biology, and §Pathology and Laboratory Medicine, St. Jude Children's Research \\ Hospital, Memphis, Tennessee 38101; and "Joint Section of Hematology-Oncology, Department of Medicine, Pritzker School of Medicine, \\ University of Chicago, Chicago, Illinois 60637
}

\begin{abstract}
DNA from a tertiary mouse cell transformant containing amplified human sequences encoding a human myeloid membrane glycoprotein, gp150, was used to construct a bacteriophage lambda library. A single recombinant phage containing 12 kilobases (kb) of human DNA was isolated, and molecular subclones were then used to isolate the complete gp150 gene from a human placental genomic DNA library. The intact gp150 gene, assembled from three recombinant phages, proved to be biologically active when transfected into NIH 3T3 cells. Molecular probes from the gp150 locus annealed with a $4.0-\mathrm{kb}$ polyadenylated RNA transcript derived from human myeloid cell lines and from tertiary mouse cell transformants. The gp150 gene was assigned to human chromosome 15 , and was subchromosomally localized to bands q25-26 by in situ hybridization. The chromosomal location of the gp150 gene coincides cytogenetically with the region assigned to the c-fes proto-oncogene, another human gene specifically expressed by myeloid cells.
\end{abstract}

\section{Introduction}

Monoclonal antibodies have been identified that recognize epitopes of cell surface glycoproteins expressed by committed human myeloid cell progenitors and subsets of more differentiated granulocytic and monocytic cells (1-6). The lineage-specific pattern of expression of these gene products during normal and malignant myeloid cell development indicates that they may play important roles as cell surface receptors, polypeptide hormone precursors, attachment factors, or recognition factors for other cells in the bone marrow microenvironment. These molecules are expressed according to defined timetables, apparently in response to signals from well-characterized colony-stimulating factors that stimulate myeloid cell proliferation and differentiation (7). Thus, the genes encoding these proteins are ideal candidates for studies of lineage-restricted transcriptional regulation during myelopoiesis.

We have biochemically characterized a cell surface glycoprotein, gp150, that is expressed in a panmyeloid fashion by committed granulocyte-monocyte progenitors and their progeny at all morphologically distinct stages of differentiation (8). Monoclonal antibodies that recognize gp150 precipitated two

Address reprint requests to Dr. Look, Department of Hematology/Oncology, St. Jude Children's Research Hospital, Memphis, TN 38101.

Received for publication 28 March 1986.

J. Clin. Invest.

(C) The American Society for Clinical Investigation, Inc.

0021-9738/86/10/0914/08 \$1.00

Volume 78, October 1986, 914-921 glycoprotein molecules of 130,000 and 150,000 molecular weight (mol wt) (gp130 and gp150) from human myeloid cell lines. Kinetic metabolic labeling experiments demonstrated that gp130 is an intracellular precursor of gp150, differing from the mature cell surface form of the glycoprotein in the composition of its $N$-linked oligosaccharide chains. A comparison of the $\left[{ }^{35}\right.$ S]methionine-labeled tryptic cleavage products of gp130 and gp150 molecules showed unequivocally that the two polypeptides represent posttranslationally modified products of a single human gene. Immunologic and biochemical studies indicate that gp150 differs from the 155,000-mol-wt myeloid cell glycoprotein recognized by the monoclonal antibodies anti-Mol, anti-Mac1 , and anti-OKM1 (9). The latter molecule assembles noncovalently with a 94,000-mol-wt glycoprotein, and inherited deficiencies of its expression on granulocytes and monocytes are associated with recurrent bacterial infections in man $(9,10)$. gp150 is also distinct from the c-fms-coded glycoprotein (possibly, the receptor for colony-stimulating factor 1 [11]) expressed on human monocytes, macrophages, and choriocarcinoma cell lines (12-15).

To isolate the gene encoding gp150, we used a DNA-mediated gene transfer system and then fluorescence-activated cell sorting to identify and segregate rare mouse cell transformants that express gp150 epitopes $(8,16)$. Biochemical studies demonstrated that these transfected mouse fibroblasts expressed bona fide human gp150 molecules that were intracellularly processed in a fashion analogous to that observed in parental myeloid cell lines. Through sequential rounds of DNA-mediated gene transfer, we were able to limit the complexity of human DNA retained by transfected cells to $<50$ kilobases $(\mathrm{kb})$ thereby defining an upper limit for the size of the gp150 gene. In addition, we identified transformed subclones that expressed unusually high levels of gp 150 at the cell surface and showed concordant amplification of a defined set of human DNA restriction fragments. Cytogenetic studies disclosed that the acquired human DNA sequences were associated with double-minute chromatin bodies. As is characteristic of extrachromosomal gene amplification, the segregation of double-minute chromatin bodies from transformed cells correlated with a loss of gp 150 expression in revertant clones.

We now report the molecular cloning of human DNA from a tertiary mouse cell transformant containing amplified gp 150 coding sequences. Probes derived from these sequences were used to isolate the complete gp150 gene from a human placental genomic DNA library. The intact gp150 gene, assembled from three recombinant phages, proved to be biologically active when transfected into mouse fibroblasts.

\section{Methods}

Cell lines. NIH 3T3 (17) [subclone 7 (18)] cells were grown as monolayer cultures in Dulbecco's modified Eagle's medium containing $10 \%$ fetal 
calf serum (FCS), ${ }^{1}$ penicillin $(100 \mathrm{U} / \mathrm{ml})$, and streptomycin $(100 \mu \mathrm{g} / \mathrm{ml})$. The human myeloid cell lines HL-60 (19) and KG-1a (20) were maintained in RPMI 1640 medium containing 15\% FCS and antibiotics. Transformed NIH 3T3 cells were cultured in medium containing $5 \%$ FCS.

Molecular cloning of gp150 sequences. A genomic DNA library was prepared from DNA of a tertiary NIH 3T3 transformant (SJ-150-B) that exhibited very high levels of gp150 expression associated with amplifcation of a limited subset of human DNA restriction fragments presumed to include the gp150 gene (16). High molecular weight DNA (150 $\mu \mathrm{g})$ from these cells was digested with limiting quantities of $\mathrm{MboI}$ restriction endonuclease for $30 \mathrm{~min}$ at $37^{\circ} \mathrm{C}$, yielding fragments of $16-\mathrm{kb}$ mean length. The unfractionated fragments $(0.5 \mu \mathrm{g})$ were mixed with $1 \mu \mathrm{g}$ of BamHI-digested EMBL3 bacteriophage lambda cloning arms (Vector Cloning Systems, San Diego, CA) and ligated with T4 DNA ligase (New England Biolabs, Beverly, MA) in $10 \mu$ l total volume for $16 \mathrm{~h}$ at $12^{\circ} \mathrm{C}$. Ligated DNA was packaged into phage particles in vitro by use of commercially obtained extracts (Vector Cloning Systems) to yield 30,000 recombinant phages, which were then used to infect strain $\mathrm{Q} 359$ bacterial cells at a density of 3,000 plaques per $150-\mathrm{mm}$ dish. The library was screened by the method of Benton and Davis (21), with nick-translated human repetitive sequences used as a probe (8). The probe was prepared by self-annealing of boiled, sonicated human placental DNA to a $C_{0} t$ of 2 (where $C_{0}$ is the concentration of DNA in moles of nucleotide per liter and $t$ is the time in seconds [22]). Hybridization was performed at $65^{\circ} \mathrm{C}$ at a monovalent cation concentration of $0.6 \mathrm{M}$, and the double-stranded DNA was recovered by fractionation on hydroxylapatite (22). Strongly hybridizing phages were plaque-purified and rescreened. Restriction endonuclease maps of cloned inserts were deduced from the results of digestion of phage DNAs and of fragments subcloned into the plasmid pBR322 (23).

Southern blots of restriction endonuclease digests of phage DNAs were hybridized with a nick-translated human repetitive sequence probe to identify fragments that did not contain repetitive sequences, and these fragments were subcloned in pBR322. Nick-translated probes prepared from these subcloned restriction fragments were used to identify recombinant bacteriophages from a human placental genomic DNA library (provided by Dr. Philip Leder of Harvard Medical School, Boston, MA)

Analysis of human sequences by southern and northern blotting. Cellular DNAs were digested with various restriction endonucleases (New England Biolabs), separated by electrophoresis in $0.8 \%$ agarose gels, and transferred to nitrocellulose (24). Probes were prepared from DNA containing human repetitive sequences or from electroeluted human restriction fragments that did not contain repetitive sequences. These DNAs were labeled to a specific activity of $1 \times 10^{8} \mathrm{dpm} / \mu \mathrm{g}$ by nick translation (25), and used in blot hybridization under stringent annealing conditions (26).

RNA was isolated by the guanidium/cesium chloride method as described by Maniatis et al. (23). Polyadenylated RNA was selected by two cycles of oligo-dT cellulose chromatography. RNA samples were analyzed by electrophoresis in $1 \%$ agarose gels containing $2.2 \mathrm{M}$ formaldehyde. RNA was transferred to nitrocellulose and hybridized according to procedures described by Thomas (27).

Transfection and expression of cloned DNA sequences. To reconstruct the gp150 gene, recombinant bacteriophage DNAs were digested to completion with the restriction endonuclease SfiI (New England Biolabs) at $50^{\circ} \mathrm{C}$ for $4 \mathrm{~h}$, precipitated with ethanol, and resuspended at a concentration of $1.0 \mu \mathrm{g} / \mu \mathrm{l}$. Mixtures of digested DNAs from different recombinants were ligated at $17^{\circ} \mathrm{C}$ for $18 \mathrm{~h}$ with $600 \mathrm{U}$ of T4 DNA ligase. Ligated DNAs were diluted to $50 \mu \mathrm{g} / \mathrm{ml}$ in $10 \mathrm{mM}$ Tris- $\mathrm{HCl}$ and $1 \mathrm{mM}$ EDTA, pH 7.4, extracted with an equal volume of Tris-HCl-saturated phenol ( $\mathrm{pH} 8.0$ ), chloroform, and isoamyl alcohol (25:24:1), and dialyzed against Tris- $\mathrm{HCl} / \mathrm{EDTA}$ overnight.

To determine whether ligated DNAs from different combinations of recombinant phages contained reconstituted, biologically active gp150

1. Abbreviation used in this paper: FCS, fetal calf serum. coding sequences, NIH $3 \mathrm{~T} 3$ cells $\left(3 \times 10^{5}\right.$ cells/35-mm petri dish) were transfected with these DNAs. Dialyzed, ligated-phage recombinant DNA $(1 \mu \mathrm{g})$ was cotransfected with DNA $(0.1 \mu \mathrm{g})$ from the cloned McDonough strain of feline sarcoma virus (SM-FeSV) containing the v-fms oncogene (28) together with sheared NIH 3T3 carrier DNA $(5 \mu \mathrm{g})$ into NIH 3T3 cells by use of the calcium phosphate technique $(29,30)$. After $18 \mathrm{~h}$ of incubation with DNA precipitates, the cells were trypsinized and plated into $75-\mathrm{cm}^{2} \mathrm{~T}$ flasks with medium containing 5\% FCS. Foci of transformed cells were enumerated $12 \mathrm{~d}$ later and then allowed to overgrow the monolayer of untransformed NIH 3T3 recipients. The efficiency of transformation in this system is $\sim 2,000$ foci/mg SM-FeSV DNA $(28,30)$.

Transformants were sorted by flow cytometry after they had been stained with the monoclonal antibody MY7 (Coulter Immunology, Hialeah, FL), which reacts with an epitope of gp150. Transformants isolated based on reactivity with MY7 were tested by flow cytometry for binding of other monoclonal antibodies that react with epitopes of gp150: DUHL60-4 (3) from Dr. Richard S. Metzgar of Duke University, Durham, NC; MCS.2 (2) from Dr. Jun Minowada of Loyola University, Chicago, IL; and SJ-D1 (31) from Dr. Joseph Mirro of St. Jude Children's Research Hospital, Memphis, TN. Indirect immunofluorescence labeling, flow cytometric analysis, and cell sorting were performed as previously described (8).

Radioiodination of cell surface proteins. Live HL-60 or transformed NIH 3T3 cells were iodinated with lactoperoxidase, and detergent lysates were immunoprecipitated and separated by electrophoresis in polyacrylamide gels containing sodium dodecyl sulfate (8). The positions of radiolabeled proteins were determined by autoradiography of the dried slab gels, using protein standards of known molecular weight.

Chromosomal localization of the gp150 gene. Somatic cell hybrids were formed by polyethylene glycol 1,000-mediated fusion of human VA2, A549, and IMR90 fibroblast cells to hamster cells (Chinese E36 or Syrian BHK-B1). The rodent cells are mutant in hypoxanthine-phosphoribosyl transferase or thymidine kinase genes, respectively, allowing the selection of hybrid cells on hypoxanthine-aminopterin-thymidine medium. Hybrids were initially grown in hypoxanthine-aminopterinthymidine medium containing $10 \mu \mathrm{M}$ ouabain to select against parental human cells. A panel of hybrid clones retaining rodent and segregating human chromosomes was analyzed for their human chromosome composition by screening for up to 34 gene-enzyme systems (32). Selected hybrids were further analyzed karyologically by Giemsa-trypsin banding (33). High molecular weight DNA and cell homogenates for isozyme analysis were prepared from the same passage of cells. The DNA was digested to completion with BamHI restriction endonuclease, electrophoretically separated by size on agarose gels, transferred to nitrocellulose, and hybridized with a nick-translated ${ }^{32} \mathrm{P}$ radiolabeled gp150-specific probe.

Two hybrid clones, EIMR 15 and EIMP2, were sequentially sorted two times by flow cytometry using the antibody BBM.1, which is specific for human $\beta_{2}$-microglobulin (34), to derive cell populations retaining or segregating human chromosome 15 . Duplicate Southern blots containing DNA from these cell populations were hybridized with nick-translated probes prepared from DNA from the gp 150 locus or a Pst 1 subgenomic fragment of $\mathrm{v}-f e s$, designated $\mathrm{v}$-fes $\mathrm{S}_{\mathrm{L}}(35,36)$.

A radiolabeled gp150-specific probe was used for in situ chromosomal hybridization to normal human metaphase cells prepared from phytohemagglutinin-stimulated peripheral blood lymphocytes. The plasmids containing gp150 sequences were nick-translated with all four ${ }^{3} \mathrm{H}$-labeled deoxynucleoside triphosphates to specific activities of 2-20 $\times 10^{7} \mathrm{dpm} /$ $\mu \mathrm{g}$. Hybridization was performed as described previously (37). Metaphase cells were hybridized with $2.0,4.0,20$, and $40 \mathrm{ng}$ probe $/ \mathrm{ml}$ of hybridization mixture. Autoradiographs were prepared with NTB-2 nuclear track emulsion (Eastman Kodak, Rochester, NY). The slides were exposed for $11 \mathrm{~d}$.

\section{Results}

Molecular cloning of gp150 sequences. DNA-mediated gene transfer was previously used to derive subclones of NIH 3T3 
cells that expressed the gp150 glycoprotein at their cell surface (8). After serial rounds of DNA transfection and cell sorting, tertiary NIH 3T3 transformants that contained limited complements of human DNA sequences with a total complexity of $<50 \mathrm{~kb}$ were isolated. One subclone (designated SJ-150-B) expressed elevated levels of $\mathrm{gp} 150$, in association with unstable amplification of the acquired human DNA sequences (16). We reasoned that a genomic DNA library prepared from the DNA of SJ-150-B cells would contain multiple copies of the gp150 gene that could be readily detected with probes representing reiterated human DNA sequences.

DNA from SJ-150-B cells was used to construct a library in the bacteriophage lambda cloning vector, EMBL3. Approximately 30,000 phage recombinants from this library were screened by filter hybridization with nick-translated human repetitive sequence DNA, and a single recombinant phage, designated $\lambda 56$, which contained $12 \mathrm{~kb}$ of human DNA, was isolated. Sites of cleavage for several restriction endonucleases were mapped within the cloned DNA of $\lambda 56$ (Fig. 1). Southern blot analysis of BamHI restriction fragments showed that they comigrated with amplified human BamHI fragments present in SJ150-B DNA (representative results are shown in lanes 1 and 2 of Fig. 2). Three contiguous fragments lacking repetitive human DNA sequences were identified and subcloned into the plasmid pBR322. Fragment 1 was a 3.5-kb BamHI-EcoRI fragment, and fragments 2 and 3 were BamHI fragments of 1.2 and $0.65 \mathrm{~kb}$ (see shaded regions of the restriction map in Fig. 1). Each of the subclones was labeled by nick translation and tested by Southern blotting procedures for hybridization to HL-60 DNA and to the

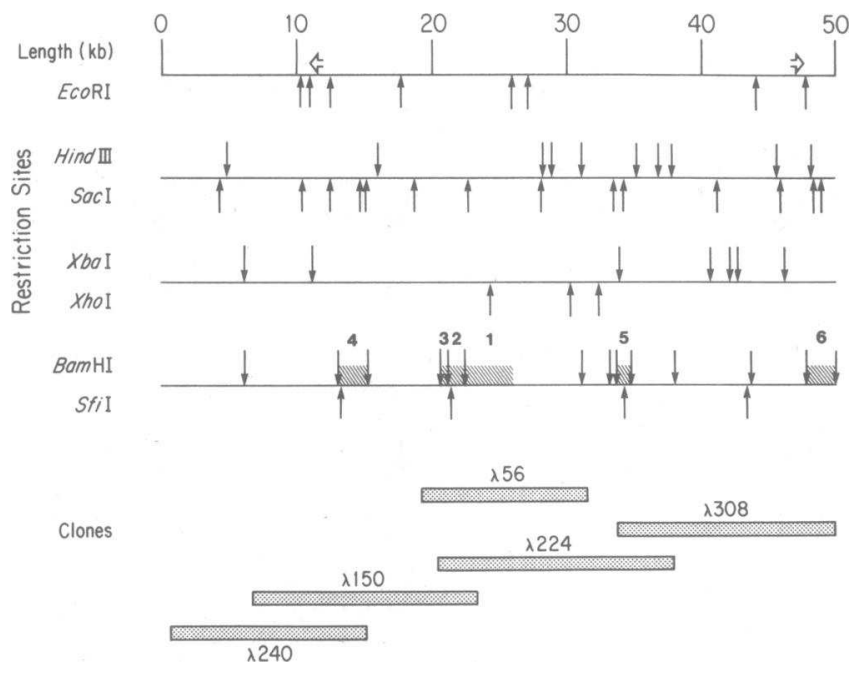

Figure 1. Restriction map of the gp150 locus, obtained from overlapping human DNA inserts in lambda phage recombinants. Clone $\lambda 56$ was isolated from a library prepared from DNA from a tertiary NIH $3 T 3$ transformant, SJ-150-B, probed with human repetitive sequences. Restriction fragments lacking human repetitive sequences (labeled 1 , 2 , and 3) were subcloned in pBR322 and used to isolate additional overlapping clones from a human placental DNA library. Two additional unique sequence restriction fragments were again subcloned (labeled 4 and 5), and used to obtain additional overlapping clones, spanning a total of $50 \mathrm{~kb}$. Unique sequence fragments 1-6 were used for Southern and Northern blot analyses of the gp150 gene (see Figs. 3 and 4). Arrows above the restriction map indicate the estimated limits of human DNA retained by the tertiary transformant, SJ-150-B, based on comparison of restriction fragments hybridizing with human repetitive sequences (Fig. 2) or unique sequence fragments 1-6 (Fig. 3).

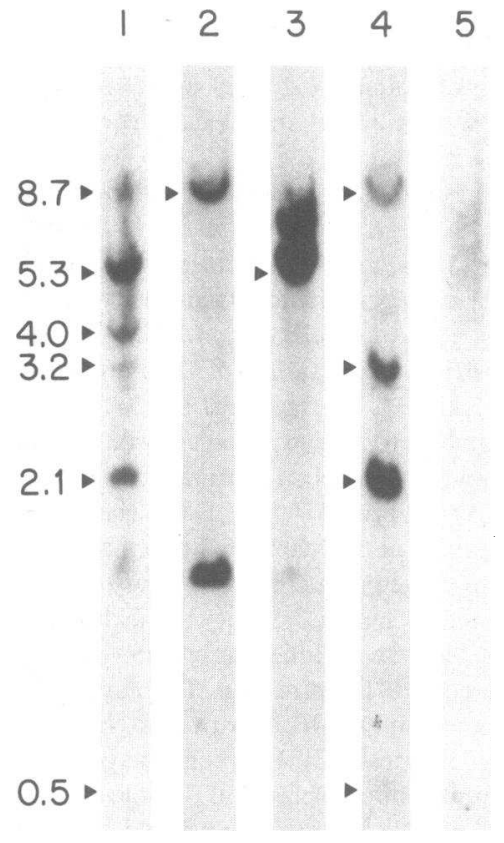

Figure 2. Southern blot analysis of BamHI restriction fragments containing human repetitive DNA sequences. The DNAs were isolated from: a tertiary mouse cell transformant (SJ-150-B) expressing high levels of gp 150 and containing amplified donor DNA sequences (lane 1); recombinant bacteriphage $\lambda 56$ (lane 2); recombinant bacteriophage $\lambda 150$ (lane 3); recombinant bacteriophage $\lambda 224$ (lane 4); and control NIH 3T3 cells (lane 5). The human sequences present in each bacteriophage are shown in Fig. 1. The estimated lengths of the hybridizing fragments in kilobases are shown at the left, and corresponding bands in lanes 2-4 are indicated by solid arrows. An additional $0.5-\mathrm{kb}$ restriction fragment is evident in an overexposed autoradiogram in DNA from both the tertiary transformant and clone $\lambda 224$, but is not visualized well in the autoradiogram shown. Hybridizing fragments in lanes 2 and 3 that do not match those in lane 1 and lack solid arrows are junctional fragments formed by ligation of human and phage DNA.

DNA of the tertiary transformant SJ-150-B. Each probe hybridized to a unique BamHI restriction fragment of corresponding length in HL-60 DNA that was amplified in the DNA from the tertiary transformant. (For representative results with probe 2, see lanes 7-9 of Fig. 3.) In addition, each probe hybridized to a single polyadenylated RNA species expressed in both HL-60 cells and transformed SJ-150-B cells (see below). Taken together, these results suggested that $\lambda 56$ contained a portion of the bona fide gp150 gene.

We used a human placental genomic library constructed in the bacteriophage cloning vector Charon 28 to obtain overlapping recombinants that spanned additional contiguous regions of the gp150 gene. This approach was chosen to ensure that the cloned human gene lacked rearrangements that could have occurred during several rounds of DNA-mediated gene transfer. Initially, a 3.5-kb EcoRI-BamHI subclone (Fig. 1, fragment 1) from the EMBL3 recombinant $\lambda 56$ was used as a probe to identify eight Charon 28 recombinants containing portions of this sequence. These eight additional clones, obtained after screening $3.6 \times 10^{5}$ phages from the library, were grown and studied in detail. Restriction maps of two clones with the largest inserts, $\lambda 150$ and $\lambda 224$, showed that they contained sequences overlapping with those of $\lambda 56$, and together spanned more than $30 \mathrm{~kb}$ of human DNA (Fig. 1). The other six recombinant phages all 
Figure 3. Southern blots probed with radiolabeled subclones derived from the gp 150 locus. Results are shown with probes prepared from restriction fragments (see Fig. 1) 4 (lanes 1-6), 2 (lanes 7-9), and 6 (lanes 10-12). BamHI (lanes 1-3 and 7-12) or HindIII (lanes 4-6) digests were prepared using DNA from: human HL60 cells (lanes 1, 4, 7, and 10); NIH 3T3 cell transformant SJ-150-B expressing v-fms and amplified gp 150 (lanes 2, 5, 8, and 11); and control NIH 3T 3 cells transformed by v-fms (lanes 3, 6, 9, and 12).

contained sequences that overlapped with those of $\lambda 150$ and $\lambda 224$, suggesting that the sequence used to probe the library was derived from a unique genetic locus. After digestion with BamHI, restriction fragments from $\lambda 150$ and $\lambda 224$ comigrated with additional human restriction fragments found in SJ-150-B DNA (Fig. 2, lanes 3 and 4). Two additional restriction fragments lacking repetitive human DNA sequences were subcloned into pBR322 (fragments 4 and 5, Fig. 1), and probes prepared from these subclones again hybridized to unique BamHI restriction fragments in HL-60 DNA and to amplified sequences in the DNA of the tertiary transformant, SJ-150-B (see lanes 1-3 of Fig. 3 for results with probe 4 ). These probes were used to identify five additional recombinants from the library, and the phages with the largest inserts, $\lambda 308$ and $\lambda 240$, extended the contiguous region of cloned DNA to $\sim 50 \mathrm{~kb}$ (Fig. 1).

An additional restriction fragment lacking human repetitive sequences (fragment 6, Fig. 1) was subcloned, and a probe prepared from this fragment hybridized to a unique restriction fragment in HL-60 DNA that was not present in DNA from the tertiary transformant, SJ-150-B (Fig. 3, lanes 10-12). Therefore, sequences recognized by this probe were not included in the human DNA retained by the tertiary mouse cell transformant and must fall outside the region encoding gp 150 . Similarly, restriction fragment 4 was found to recognize an alternative HindIII restriction fragment in DNA from the tertiary transformant compared with HL-60 DNA (Fig. 3, lanes 4-6), suggesting that human DNA encoding gp 150 did not include the single HindIII site present in the cloned DNA of $\lambda 240$. From these results, and from a detailed comparison of cloned restriction fragments containing human repetitive sequences with those found in DNA from the tertiary transformant, it was possible to estimate the approximate boundaries of the gp 150 locus retained by SJ-150B cells, as shown by the arrows on the top line of Fig. 1. These measurements limit the complexity of the gp150 gene to $<35 \mathrm{~kb}$.

Identification of a polyadenylated 4.0- $k b$ RNA with gp150specific probes. Since five of six plasmid subclones containing unique human DNA sequences hybridized to amplified restriction fragments in the DNA of SJ-150-B cells, we tested these subclones for the presence of coding sequences. Each plasmid was radiolabeled and hybridized to Northern blots containing polyadenylated RNA purified from five cell lines: the human myeloid cells, HL-60 and KG-1a; the tertiary transformant, SJ150-B, which shows amplified gp150 expression; an independently derived v-fms transformant lacking human DNA sequences; and the nontransformed parental NIH 3T3 cell line.
A 4.0-kb polyadenylated RNA species was detected with probes prepared from fragments $1,2,3$, and 5 in RNA from HL-60, KG-1a, and SJ-150-B cells, but was not seen when control RNAs were used (representative results are shown with probe 5 in Fig. 4). Whereas similar amounts of polyadenylated RNAs were run in each lane, the autoradiographic exposure time for the band in Fig. 4, lane 3 was considerably shorter, consistent with the presence of more gp150 mRNA in SJ-150-B cells (see legend). The length of this messenger RNA would be sufficient to encode the 110,000-mol-wt nonglycosylated polypeptide that has been identified with monoclonal antibodies specific for $\mathrm{gp} 150$ in tunicamycin-treated HL-60 cells (8). Since together these four probes span about $6 \mathrm{~kb}$ of human DNA, they must contain unique intron- as well as exon-related sequences. The identifcation of a single messenger RNA of an appropriate size in human myeloid cells, its absence in mouse fibroblasts, and its increased expression by tertiary mouse cell subclones that overexpress gp 150, indicate that this transcript very likely encodes the gp150 protein.

In contrast to the results with probes $1,2,3$, and 5 , the probe prepared from subclone 4 did not hybridize to any mRNA, indicating that it contains exclusively intron sequences or that it lies outside of the coding region of the gp 150 gene. Consonant with the latter interpretation is the fact that EcoRI and SacI fragments containing human repetitive sequences and mapping upstream of fragment 4 were not detected in SJ-150-B DNA.

Cloned DNA is biologically active and encodes gp150. To test for the ability of the cloned human sequences to encode gp150, we reconstructed contiguous stretches of human DNA from phages with overlapping inserts, and cotransfected this DNA back into mouse cells. To realign the human sequences in their correct order, we digested equimolar mixtures of phage DNAs to completion with the restriction endonuclease $S f i$ and religated these DNAs to one another. Sfil proved an ideal enzyme for these experiments, since each restriction site ( $G G C C N_{4} \downarrow N G G C C$ ) yields unique $3^{\prime}$ and $5^{\prime}$ termini, so that the digested fragments from overlapping phage inserts can religate only in the correct orientation. In addition, the enzyme recog-
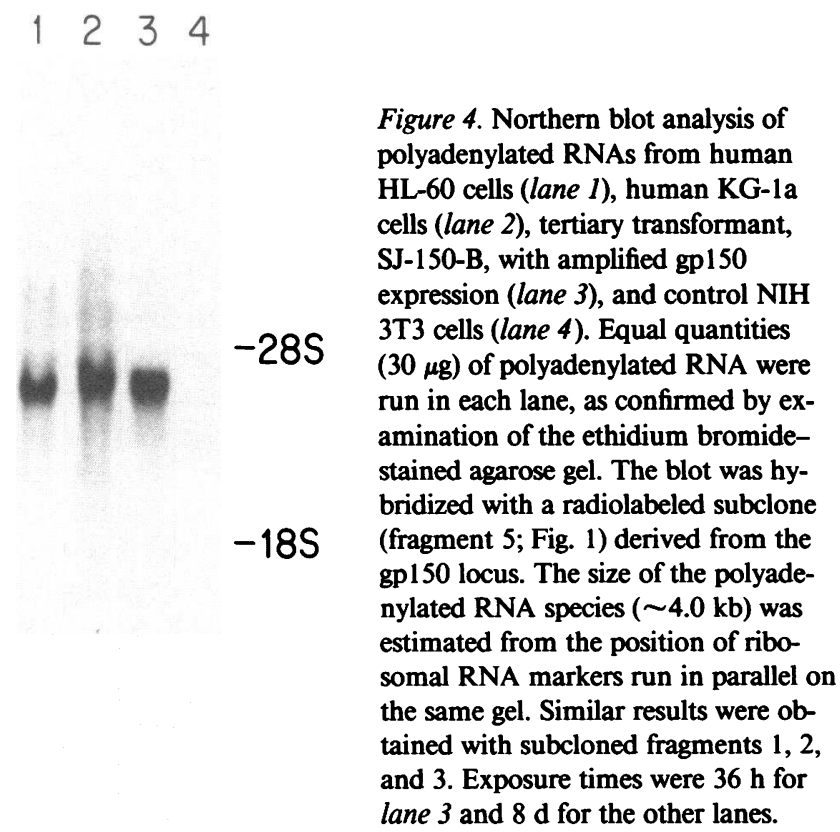
nizes restriction sites in regions of overlap between inserts of the four phage clones that span the gp150 locus (Fig. 1), but does not digest lambda phage DNA. When equimolar mixtures of phage DNAs restricted with $S$ fiI were ligated to one another, there was a $50 \%$ chance of joining two overlapping phages, or one chance in eight of reforming a complete contiguous segment of $50 \mathrm{~kb}$ from the four phage clones (Fig. 1).

NIH 3T3 cells were transfected with $1 \mu \mathrm{g}$ of ligated phage DNA, together with $5 \mu \mathrm{g}$ of NIH 3T3 cell carrier DNA and 0.2 $\mu \mathrm{g}$ of cloned $\mathrm{v}-f m s$ DNA. Morphologically transformed cells were then allowed to overgrow their nontransformed counterparts in medium containing 5\% serum. 3 wk after transfection, flow cytometry was used to select for the presence of transfected cells binding the gp150-specific monoclonal antibody, MY7. Cells receiving ligated DNA from mixtures of $S$ fiI digests of either $\lambda 308+\lambda 224+\lambda 150$ or $\lambda 308+\lambda 224+\lambda 150+\lambda 240$ yielded from 10 to $50 \% \mathrm{gp} 150$-positive cells after one round of selection by cell sorting. Therefore, the $45-\mathrm{kb}$ human DNA segment included in the overlapping inserts of three phages $(\lambda 308+\lambda 224$ $+\lambda 150)$ contained the entire gp 150 coding sequence. Transfected NIH 3T3 cells receiving unligated phage DNAs, either individually or in mixtures, did not yield cells positive for MY7-binding after three successive rounds of cell sorting, demonstrating that the gp150 gene must be assembled in vitro to obtain expression by transfected cells.

Cells transfected with ligated DNAs from $\lambda 308+\lambda 224$ $+\lambda 150$ were selected twice by flow cytometric cell sorting, and the fluorescence-positive population was seeded as single cells in semisolid medium. Subclones with high levels of MY7 binding were derived from agar colonies and tested for binding with other antibodies specific for gp 150 epitopes. Fig. $5 A$ shows representative results with one subclone and indicates that the cells expressed epitopes detected by four different monoclonal antibodies to gp150.

Viable cells of two independent subclones were enzymatically iodinated with lactoperoxidase, and detergent lysates were immunoprecipitated with a mixture of two monoclonal antibodies, MY7 and DU-HL60-4. Fig. $5 B$ shows that polypeptides with the mobility of gp150 were detected in lysates from control human HL-60 cells as well as in the two transfected NIH 3T3 subclones. No specifically precipitable polypeptide was detected in lysates of cells transfected by v-fms alone. The more rapid mobility of gp150 molecules in mouse cells as compared with HL-60 cells has been observed previously (8), and appears to be due to differences in glycosylation in the different cell types.

Localization of the gp150 gene to human chromosome 15, bands q25-26. A panel of somatic cell hybrids, each containing different human chromosomes, was used to map the gp 150 gene to a human chromosome. A 1.2-kb BamHI fragment (fragment 2, Fig. 1) hybridized strongly to an identical restriction fragment in human, but not hamster, DNA, and was annealed to BamHIdigested DNAs from a panel of human $\times$ hamster somatic cell hybrid clones. The results showed concordance between the presence of the 1.2-kb human BamHI restriction fragment and human chromosome 15 (Table I). Only one of 41 hybrid clones showed discordancy between the presence of $\mathrm{gp} 150$ sequences and human chromosome 15 , consonant with the frequency of chromosomal breaks in somatic cell hybrids and within a range expected for linked markers (38). Cells from several hybrid cell lines were sorted by flow cytometry, using antibodies to $\beta_{2}$-microglobulin, also encoded by a gene on human chromosome 15 (39). As shown in Fig. $6 A$ and $B$, two independent hybrids gave

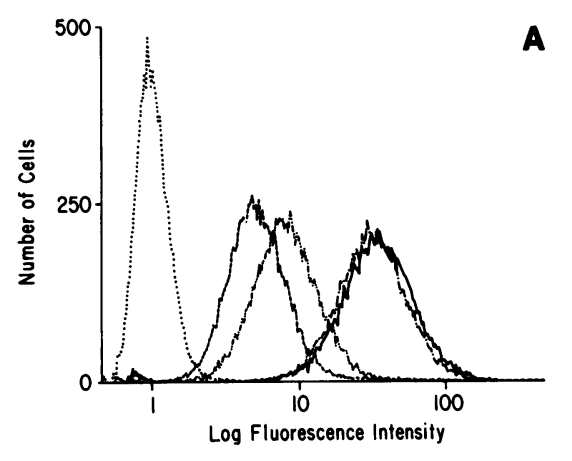

$\mathbf{B}$

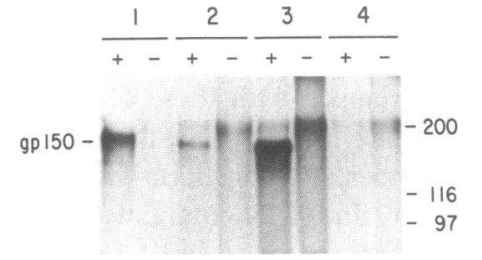

Figure 5. Expression of gp 150 on the plasma membrane of NIH 3T3 cells transfected with ligated DNA from mixtures $S$ fiI digests of $\lambda 308$ $+\lambda 224+\lambda 150$. Flow cytometric profiles $(A)$ obtained after binding of antibodies specific for epitopes of gp 150 to cells from a representative subclone, which was derived from transfected cells sorted two times for the $2 \%$ of cells with the brightest fluorescence after staining with MY7. Positive fluorescence profiles that resulted from testing of cells with monoclonal antibodies MY7 (-), MCS.2 (•-•-), SJ-D1 (•--.-), and DU-HL60-4 (-- -), compared to results with mouse myeloma protein $(\cdot \cdots)$ are shown. $(B)$ Viable cells were enzymatically radioiodinated and detergent lysates were immunoprecipitated with a mixture of MY7 and DU-HL60-4 (+) or control mouse myeloma protein $(-)$. Labeled proteins in immune complexes were denatured and analyzed in polyacrylamide gels containing sodium dodecyl sulfate. Results are shown for HL-60 cells (1), two independently derived subclones of NIH 3 T3 cells transfected with ligated phage DNAs (2 and 3), and control NIH 3T3 cells transformed by v-fms alone (4).

rise to cell populations that either retained or segregated human chromosome 15 , based on whether they expressed (solid lines) or lost (dotted lines) $\beta_{2}$-microglobulin from their cell surface. The c-fes proto-oncogene has previously been assigned to the long arm of human chromosome 15 (40), and has served as an internal standard in these studies. Fig. $6 C$ shows that a v-fes oncogene probe $(35,36)$ detected two $\mathrm{BamHI}$ fragments in human DNA (lane 1). The c-fes fragment of $\sim 4 \mathrm{~kb}$ was detected only in the DNA of cells that expressed $\beta_{2}$-microglobulin (lanes 2 and 4 ). The gp150 probe similarly annealed only to DNA of $\beta_{2}$-microglobulin-positive (lanes 7 and 9) but not negative (lanes 8 and 10 ) hybrids.

In situ hybridization of the gp150-specific probe to normal human metaphase chromosomes sublocalized the gp150 locus to the distal long arm of chromosome 15, bands q25-26. Of 100 metaphase cells, 32 were labeled on region q2, bands $q 25$ to q26, of one or both chromosome 15 homologs; these sites represented $20.5 \%(36 / 176)$ of all labeled sites $(P<0.0005)$. The distribution of grains on 44 labeled chromosome $15 \mathrm{~s}$ indicated significant clustering at bands $15 q 25$ to q26 (Fig. 7). Of 44 total labeled sites on chromosome $15,36(82 \%)$ were located on $15 q 25$ to q26. The remaining grains on this chromosome were distributed along the proximal long arm and on the short arm. Similar results were obtained in the analysis of metaphase cells from 
Table I. Rodent $\times$ Human Hybrid Clones

\begin{tabular}{|c|c|c|c|c|c|}
\hline \multirow{2}{*}{$\begin{array}{l}\text { Human } \\
\text { chromosome }\end{array}$} & \multicolumn{4}{|c|}{ gp150 gene/human chromosome } & \multirow{2}{*}{$\begin{array}{l}\text { Percent } \\
\text { asynteny }\end{array}$} \\
\hline & $+1+$ & $+1-$ & $-1+$ & $-1-$ & \\
\hline 1 & 7 & 10 & 2 & 20 & 31 \\
\hline 2 & 8 & 10 & 0 & 21 & 26 \\
\hline 3 & 6 & 7 & 2 & 18 & 27 \\
\hline 4 & 9 & 4 & 1 & 15 & 17 \\
\hline 5 & 4 & 12 & 2 & 18 & 39 \\
\hline 6 & 12 & 4 & 4 & 15 & 24 \\
\hline 7 & 3 & 10 & 2 & 17 & 38 \\
\hline 8 & 5 & 12 & 2 & 19 & 37 \\
\hline 9 & 10 & 3 & 8 & 13 & 32 \\
\hline 10 & 6 & 10 & 4 & 15 & 40 \\
\hline 11 & 12 & 5 & 2 & 20 & 18 \\
\hline 12 & 11 & 7 & 4 & 17 & 28 \\
\hline 13 & 6 & 6 & 5 & 14 & 35 \\
\hline 14 & 12 & 7 & 6 & 13 & 34 \\
\hline 15 & 17 & 1 & 0 & 23 & 2 \\
\hline 16 & 7 & 6 & 6 & 13 & 38 \\
\hline 17 & 6 & 7 & 6 & 14 & 39 \\
\hline 18 & 5 & 9 & 2 & 17 & 33 \\
\hline 19 & 6 & 12 & 3 & 19 & 42 \\
\hline 20 & 8 & 9 & 8 & 12 & 46 \\
\hline 21 & 2 & 10 & 5 & 15 & 47 \\
\hline 22 & 6 & 7 & 2 & 18 & 27 \\
\hline $\mathbf{X}$ & 17 & 1 & 17 & 6 & 44 \\
\hline
\end{tabular}

Somatic cell hybrids were scored for the presence $(+)$ or absence $(-)$ of specific human chromosomes by assaying gene-enzyme systems (32, 33) and for the presence or absence of gp150 coding sequences by Southern blot hybridization.

two other hybridizations (Table II). These results agree with the data in Table I, and also indicate that the gp 150 locus is located at the same region of chromosome 15 as c-fes (40).

\section{Discussion}

A tertiary mouse cell transformant selected for its amplified expression of $\mathrm{gp} 150$, a human myeloid membrane antigen, proved an ideal source of genomic DNA probes specific for the gp150 gene. We subsequently used a human placental DNA library to obtain molecular clones spanning the entire gp150 locus to avoid potential rearrangements that might have occurred during gene transfer. Three of these clones, when assembled in the correct orientation in vitro, directed gp 150 expression when transfected back into mouse fibroblasts, confirming that together they contained the biologically active gene. Unique sequence probes from this locus annealed to a 4.0-kb polyadenylated RNA species expressed in myeloid cells and of sufficient length to encode the unglycosylated polypeptide (8). These same probes were used to assign the gp150 gene to human chromosome 15 , bands q25-26.

The chromosomal location of the gp 150 locus coincides with the regional assignment of the human c-fes proto-oncogene. This is of potential interest because the c-fes gene has recently been shown to be expressed by myeloid cells, in a pattern similar to that of gp 150 (41-43). These two genes are encoded by separate loci, since v-fes probes $(35,36)$ do not hybridize to cloned sequences spanning the gp150 gene (Look, A. T., and C. J. Sherr, unpublished results); nor do the two loci have similar restriction maps. Like the c-fes gene, gp150 sequences are distal to the

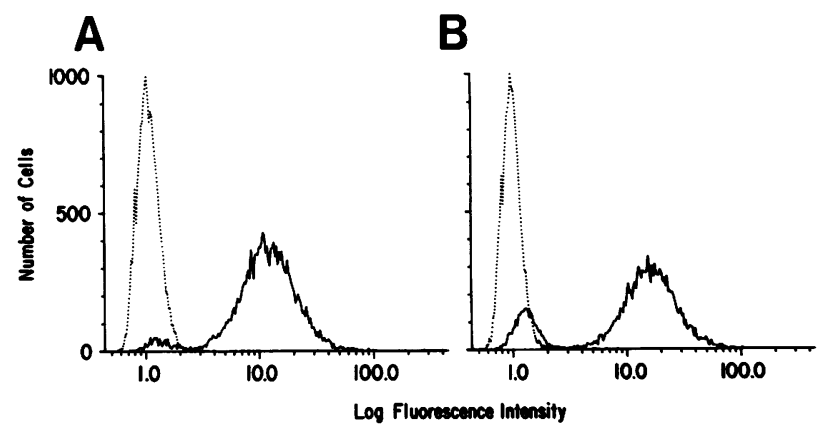

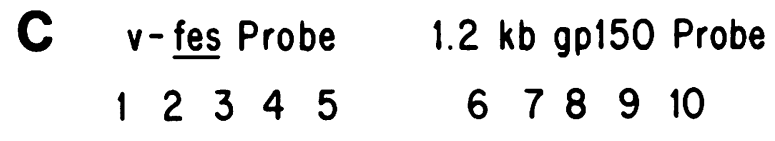
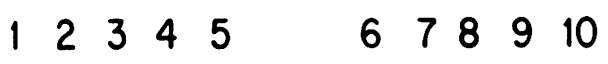

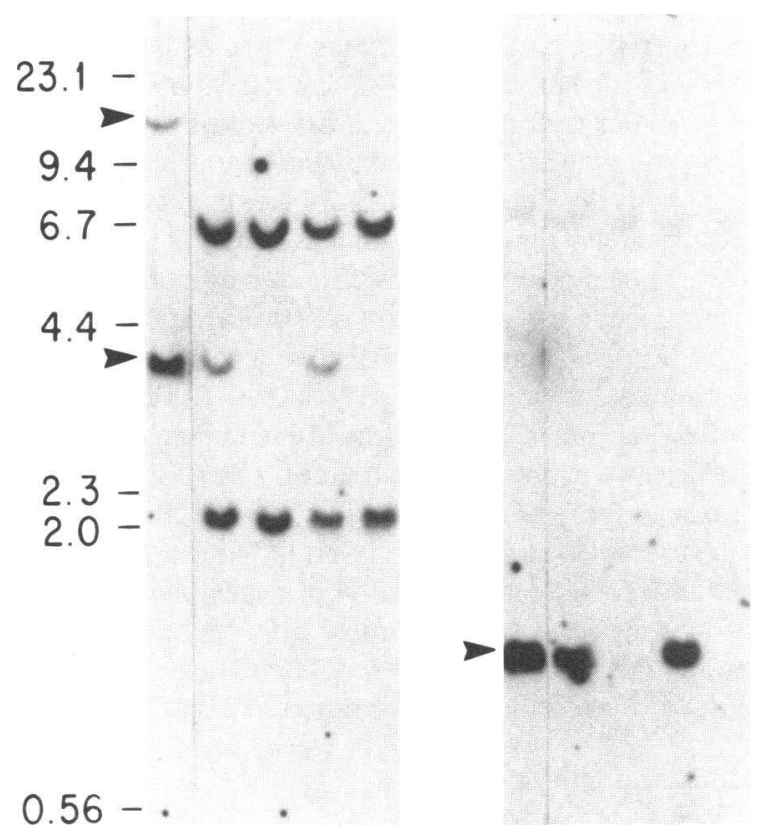

Figure 6. Two hamster $\times$ human somatic cell hybrid clones were sorted for expression of human $\beta_{2}$-microglobulin previously assigned to human chromosome 15 . Fluorescence profiles from the two sorting experiments are shown in $A$ and $B$, respectively. Each hybrid clone was heterogeneous for chromosome 15 , and gave rise to $\beta_{2}$-microglobulin-positive (solid line) and -negative (dotted line) populations. DNA from sorted populations was digested with $B a m H I$ and analyzed by Southern blotting using v-fes and gp 150 probes $(C)$. Human control DNA was analyzed in lanes 1 and 6 . Results with hybrid DNAs from $\beta_{2}$-microglobulin-positive clones are in lanes $2,4,7$, and 9, and from $\beta_{2}$-microglobulin-negative clones in lanes $3,5,8$, and 10 . The arrows mark the positions of informative human BamHI fragments.

breakpoint of a translocation involving chromosome 15 , $t(15 ; 17)(q 22 ; q 21.1)$, which has been associated with acute promyelocytic leukemia.

Similar gene transfer systems have been used by other investigators to obtain biologically active clones of human genes whose products are expressed at the cell surface. The gene encoding the human transferrin receptor, as well as the T8 and T4 genes, were each cloned after cotransfection of cellular DNA 
Table II. In Situ Chromosomal Hybridization of a gp150 Probe

\begin{tabular}{|c|c|c|c|c|c|}
\hline \multirow[b]{2}{*}{ Hybridization } & \multirow{2}{*}{$\begin{array}{l}\text { No. of metaphase } \\
\text { cells analyzed }\end{array}$} & \multirow{2}{*}{$\begin{array}{l}\text { Total no. of } \\
\text { labeled sites }\end{array}$} & \multicolumn{2}{|l|}{ No. of labeled sites } & \multirow[b]{2}{*}{$x^{2}$} \\
\hline & & & Chromosome 15 & Bands q25-26 & \\
\hline 1 & 100 & 176 & $44(25 \%)$ & $36(20.5 \%)$ & $236^{*}$ \\
\hline 2 & 100 & 200 & $36(18 \%)$ & $29(14.5 \%)$ & $122^{*}$ \\
\hline 3 & 150 & 315 & $56(17.8 \%)$ & $44(14 \%)$ & $186^{*}$ \\
\hline
\end{tabular}

* $\chi^{2}$ value calculated for chromosome 15 corresponds to $P<0.0005$.

from human cell lines with the cloned herpes simplex thymidine kinase gene into thymidine kinase-deficient mouse L cells (4449). Why mouse fibroblasts can be induced to express transfected human genes that are normally expressed in a highly differentiation-specific fashion by human hematopoietic cells has not been resolved. Hsu et al. (50) observed that transfected mouse L cells can express the $T$ cell-specific $T 8$ molecule even when the donor DNA is extracted from human tissues (e.g., placenta or kidney) that normally do not express the T8 gene. Thus, the factors that normally regulate the expression of human differentiation-associated genes appear to be inactive in murine fibroblasts containing transfected human DNA. It may be that the gene is truncated or rearranged so that regulatory sequences in the $5^{\prime}$ promoter region of the gene are altered, or that host cell enhancer sequences override the endogenous control elements. Alternatively, negative regulatory factors that normally suppress expression of the gene in human cells may not be present in mouse cells or mouse regulatory factors may not recognize human DNA sequences. In the case of gp150, aberrant regulation may not be an issue, since this particular gene product is expressed by human foreskin fibroblasts (Look, A. T., unpublished results). However, other human myeloid membrane molecules that are efficiently expressed by mouse fibroblasts after transfection, such as gp67 (16), resemble the T4 and T8 molecules and are not expressed at detectable levels in human fibroblasts. For the latter molecules, a comparison of regulatory regions of the genes in transfected cells with those from human genomic DNA libraries may resolve whether specific rearrangements that could account for abnormal gene expression in mouse fibroblasts

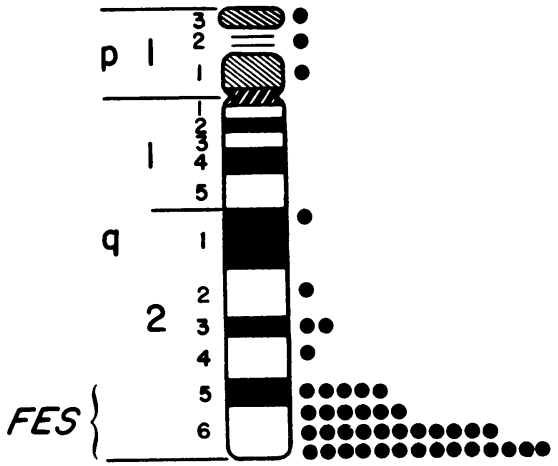

15

Figure 7. In situ chromosomal hybridization of a ${ }^{3} \mathrm{H}$-labeled gp 150 specific probe (fragment 1; Fig. 1) to normal human metaphase chromosomes prepared from phytohemagglutinin-stimulated peripheral blood lymphocytes. The distribution of grains on 44 labeled chromosome 15 s (black circles) indicated significant clustering at bands $15 \mathrm{q} 25$ to q26. Of 100 metaphase cells examined, 32 were labeled on bands q25 to q26 of one or both chromosome 15 homologs, with the largest number of grains at band q26. The gene encoding gp150 is localized to the same chromosomal region as c-fes. have occurred during transfection. In addition, the identification and classification of regulatory sequences in these genes may eventually permit the programming of other coding sequences in a lineage-specific manner in myeloid cells.

\section{Acknowledgments}

We thank Edward Wingfield, Cheryl Pruitt, Sandra Kaufman, Mary Urcan, and Rafael Espinosa for excellent technical assistance, John Gilbert for editorial review, and Micheal Kamarck, Janet D. Rowley, and Manuel O. Diaz for helpful discussion.

This work was supported by grant CA-42804 (St. Jude), Cancer Center grant CA-21765 (St. Jude), Leukemia Program Project grant CA-20180 (St. Jude), Clinical Investigator Award CA-01013 (Dr. Peiper), U. S. Department of Energy contract DE-AC02-80EV10360 (University of Chicago), U. S. Public Health Service grants CA-16910 and GM-07190 (University of Chicago), and by the American Lebanese Syrian Associated Charities of St. Jude Children's Research Hospital.

Dr. Le Beau is a Special Fellow of the Leukemia Society of America.

\section{References}

1. Griffin, J. D., J. Ritz, L. M. Nadler, and S. F. Schlossman, 1981. Expression of myeloid differentiation antigens on normal and malignant myeloid cells. J. Clin. Invest. 68:932-941.

2. Bernard, A., L. Boumsell, and C. Hill. 1984. Joint report of the first international workshop on human leucocyte differentiation antigens by the investigators of the participating laboratories. In Leucocyte Typing. A. Bernard, L. Boumsell, J. Dausset, C. Milstein, and S. F. Schlossman, editors. Springer-Verlag, Berlin. 82-108.

3. McKolanis, J. R., O. J. Finn, and R. S. Metzgar. 1983. Characterization of human myelomonocytic antigens using monoclonal antibodies. In Non-HLA Antigens in Health, Aging and Malignancy. E. Cohen and D. P. Singal, editors. Alan R. Liss, New York. 145-156.

4. Griffin, J. D., J. Ritz, R. P. Beveridge, J. M. Lipton, J. F. Daley, and S. F. Schlossman. 1983. Expression of MY7 antigen on myeloid precursor cells. Int. J. Cell Cloning. 1:33-48.

5. Bernstein, I. D., R. G. Andrews, S. F. Cohen, and B. E. McMasters. 1982. Normal and malignant human myelocytic and monocytic cells identified by monoclonal antibodies. J. Immunol. 128:876-881.

6. Andrews, R. G., B. Torok-Storb, and I. D. Bernstein. 1983. Myeloid-associated differentiation antigens on stem cells and their progeny identified by monoclonal antibodies. Blood. 62:124-132.

7. Metcalf, D. 1985. The granulocyte-macrophage colony-stimulating factors. Science (Wash. DC). 229:16-22.

8. Look, A. T., S. C. Peiper, M. B. Rebentisch, R. A. Ashmun, M. F. Roussel, C. W. Rettenmier, and C. J. Sherr. 1985. Transfer and expression of the gene encoding a human myeloid membrane antigen (gp150). J. Clin. Invest. 75:569-579.

9. Dana, N., R. F. Todd III, J. Pitt, T. A. Springer, and M. A. Arnaout. 1984. Deficiency of a surface membrane glycoprotein (Mol) in man. $J$. Clin. Invest. 73:153-159.

10. Anderson, D. C., F. C. Schmalstieg, M. A. Arnaout, S. Kohl, M. F. Tosi, N. Dana, G. J. Buffone, B. J. Hughes, B. R. Brinkley, W. D. Dickey, J. S. Abramson, T. Springer, L. A. Boxer, J. M. Hollers, and C. W. Smith. 1984. Abnormalities of polymorphonuclear leukocyte function associated with a heritable deficiency of high molecular weight surface glycoproteins (GP138). Common relationship to diminished cell adherence. J. Clin. Invest. 74:536-551. 
11. Sherr, C. J., C. W. Rettenmier, R. Sacca, M. F. Roussel, A. T. Look, and E. R. Stanely. 1985. The c-fms proto-oncogene product is related to the receptor for the mononuclear phagocyte growth factor, CSF-1. Cell. 41:665-676.

12. Sariban, E., T. Mitchell, and D. Kufe. 1985. Expression of the c-fms proto-oncogene during human monocytic differentiation. Nature (Lond.). 316:64-66.

13. Nienhuis, A. W., H. F. Bunn, P. H. Turner, T. V. Gopal, W. G. Nash, S. J. O'Brien, and C. J. Sherr. 1985. Expression of the human c-fms protooncogene in hematopoietic cells and its deletion in the $5 \mathrm{q}^{-}$ syndrome. Cell. 42:421-428.

14. Woolford, J., V. Rothwell, and L. Rohrschneider. 1985. Characterization of the human c-fms gene product and its expression in cells of the monocyte-macrophage lineage. Mol. Cell. Biol. 5:3458-3466.

15. Rettenmier, C. W., R. Sacca, W. L. Furman, M. F. Roussel, J. T. Holt, A. W. Nienhuis, E. R. Stanley, and C. J. Sherr. 1986. Expression of the human c-fms proto-oncogene product (CSF-1 receptor) on peripheral blood mononuclear cells and choriocarcinoma cell lines. $J$. Clin. Invest. 77:1740-1746.

16. Look, A. T., S. C. Peiper, E. C. Douglass, J. M. Trent, and C. J. Sherr. 1986. Amplification of genes encoding human myeloid membrane antigens after DNA-mediated gene transfer. Blood. 67:637-645.

17. Jainchill, J. L., S. A. Aaronson, and G. J. Todaro. 1969. Murine sarcoma and leukemia viruses: assay using clonal lines of contact inhibited mouse cells. J. Virol. 4:549-553.

18. Lowy, D. R., E. Rands, and E. M. Scolnick. 1978. Helper-independent transformation by unintegrated Harvey sarcoma virus DNA. J. Virol. 26:291-298.

19. Collins, S. J., F. W. Ruscetti, R. E. Gallagher, and R. C. Gallo. 1978. Terminal differentiation of human promyelocytic leukemia cells induced by dimethyl sulfoxide and other polar compounds. Proc. Natl. Acad. Sci. USA. 75:2458-2462.

20. Koeffler, H. P., R. Billing, A. J. Lusis, R. Sparkes, and D. W. Golde. 1980. An undifferentiated variant derived from the human acute myelogenous leukemia cell line (KG-1). Blood. 56:265-273.

21. Benton, W. D., and R. W. Davis. 1977. Screening $\lambda g t$ recombinant clones by hybridization to single plaques in situ. Science (Wash. DC). 196:180-182.

22. Britten, R. J., and D. E. Kohne. 1968. Repeated sequences in DNA. Science (Wash. DC). 161:529-540.

23. Maniatis, T., E. F. Fritsch, and J. Sambrook. 1982. Molecular Cloning. A Laboratory Manual Cold Spring Harbor Laboratory, Cold Spring Harbor, NY. 196-197.

24. Southern, E. M. 1975 . Detection of specific sequences among DNA fragments separated by gel electrophoresis. J. Mol. Biol. 98:503517.

25. Rigby, P. W. J., M. Dieckmann, C. Rhodes, and P. Berg. 1977. Labeling deoxyribonucleic acid to high specific activity in vitro by nick translation with DNA polymerase I. J. Mol. Biol. 113:237-251.

26. Sherr, C. J., L. A. Fedele, L. Donner, and L. P. Turek. 1979. Restriction endonuclease mapping of unintegrated proviral DNA of Synder-Theilen feline sarcoma virus: localization of sarcoma-specific sequences. J. Virol. 32:860-875.

27. Thomas, P. S. 1983. Hybridization of denatured RNA transferred or dotted to nitrocellular paper. Methods Enzymol. 100:255-266.

28. Donner, L., L. A. Fedele, C. F. Garon, S. J. Anderson, and C. J. Sherr. 1982. McDonough feline sarcoma virus: characterization of the molecularly cloned provirus and its feline oncogene (v-fms). J. Virol. 41: 489-500.

29. Graham, F. L., A. J. Van der Eb. 1973. Transformation of rat cells by DNA of human adenovirus 5. Virology. 54:536-539.

30. Roussel, M. F., C. W. Rettenmier, A. T. Look, and C. J. Sherr. 1984. Cell surface expression of $v$-fms-coded glycoproteins is required for transformation. Mol. Cell Biol. 4:1999-2009.

31. Mirro, J., Jr., S. Melvin, D. Metzger, A. Look, and S. Murphy. 1984. Changes in cell surface antigen expression during myelocytic and monocytic cell differentiation. In Leucocyte Typing. A. Bernard, L. Boumsell, J. Dausset, C. Milstein, and S. F. Schlossman, editors. SpringerVerlag, Berlin. 442-446.
32. O'Brien, S. J., J. M. Simonson, and M. Eichelbuger. 1982. Genetic analysis of hybrid cells using isozyme markers as monitors of chromosomal segregation. In Techniques in Somatic Cell Genetics. J. W. Shay, editor. Plenum Publishing Corp., New York. 342-370.

33. Lemons, R. S., W. G. Nash, S. J. O'Brien, R. E. Benveniste, and C. J. Sherr. 1978. A gene (Bevi) on human chromosome 6 is an integration site for baboon type C DNA provirus in human cells. Cell. 14:995-1005.

34. Kamarck, M. E., J. A. Barbosa, and F. H. Ruddle. 1982. Somatic cell genetic analysis of HLA-A, B, C and human $\beta_{2}$-microglobulin expression. Somatic Cell Genet. 8:385-402.

35. Sherr, C. J., L. A. Fedele, M. Oskarsson, J. Maizel, and G. F. Vande Woude. 1980. Molecular cloning of Synder-Theilen feline leukemia and sarcoma viruses: comparative studies of feline sarcoma virus with its natural helper and with Moloney murine sarcoma virus. J. Virol. 32:200-212.

36. Franchini, G., J. Even, C. J. Sherr, and F. Wong-Staal. 1981. Onc sequences (v-fes) of Snyder-Theilen feline sarcoma virus are derived from noncontiguous regions of a cat cellular gene (c-fes). Nature (Lond.). 290:154-157.

37. Le Beau, M. M., C. A. Westbrook, M. O. Diaz, and J. D. Rowley. 1985. C-src is consistently conserved in the chromosomal deletion (20q) observed in myeloid disorders. Proc. Natl. Acad. Sci. USA. 82:66926696.

38. Shows, T. B. 1972. Genetics of human-mouse somatic cell hybrids: linkage of human genes for isocitrate dehydrogenase and malate dehydrogenase. Biochem. Genet. 7:193-204.

39. Goodfellow, P. N., E. A. Jones, V. van Heyningen, E. Solomon, M. Bobrow, V. Miggiano, and W. F. Bodmer. 1975. The $\beta_{2}$-microglobulin gene is on chromosome 15 and not in the HL-A region. Nature (Lond.). 254:267-269.

40. Harper, M. E., G. Franchini, J. Love, M. I. Simon, R. C. Gallo, and F. Wong-Staal. 1983. Chromosomal sublocalization of human cmyb and c-fes cellular oncogenes. Nature (Lond.). 304:169-181.

41. Feldman, R. A., J. L. Gabrilove, J. P. Tam, M. A. S. Moore, and H. Hanafusa. 1985. Specific expression of the human cellular $f p s / f e s-$ encoded protein NCP92 in normal and leukemic myeloid cells. Proc. Natl. Acad. Sci. USA. 82:2379-2383.

42. MacDonald, I., J. Levy, and T. Pawson. 1985. Expression of the mammalian c-fes protein in hematopoietic cells and identification of a distinct fes-related protein. Mol. Cell. Biol. 5:2543-2551.

43. Samarut, J., B. Mathey-Prevot, and H. Hanafusa. 1985. Preferential expression of the c-fps protein in chicken macrophages and granulocytic cells. Mol. Cell. Biol. 5:1067-1072.

44. Kuhn, L. C., A. McClelland, and F. H. Ruddle. 1984. Gene transfer, expression, and molecular cloning of the human transferrin receptor gene. Cell. 37:95-103.

45. McClelland, A., L. C. Kuhn, and F. H. Ruddle. 1984. The human transferrin receptor gene: genomic organization, and the complete primary structure of the receptor deduced from a cDNA sequence. Cell. 39:267-274.

46. Kavathas, P., V. P. Sukhatme, L. A. Herzenberg, and J. R. Parnes. 1984. Isolation of the gene encoding the human T-lymphocyte differentiation antigen Leu-2 (T8) by gene transfer and cDNA subtraction. Proc. Natl. Acad. Sci. USA. 81:7688-7692.

47. Sukhatme, V. P., K. C. Sizer, A. C. Vollmer, T. Hunkapiller, and J. R. Parnes. 1985. The T cell differentiation antigen Leu-2/T8 is homologous to immunoglobulin and $\mathrm{T}$ cell receptor variable regions. Cell. 40:591-597.

48. Littman, D. R., Y. Thomas, P. J. Maddon, L. Chess, and R. Axel. 1985. The isolation and sequence of the gene encoding T8: a molecule defining functional classes of T lymphocytes. Cell. 40:237-246.

49. Maddon, P. J., D. R. Littman, M. Godfrey, D. E. Maddon, L. Chess, and R. Axel. 1985. The isolation and nucleotide sequence of a cDNA encoding the $T$ cell surface protein T4: a new member of the immunoglobulin gene family. Cell. 42:93-104.

50. Hsu, C., P. Kavathas, and L. A. Herzenberg. 1984. Cell-surface antigens expressed on L-cells transfected with DNA from non-expressing cells. Nature (Lond.). 312:68-69. 